\title{
LA REFORMA DEL DERECHO INGLÉS EN MATERIA DE CLÁUSULAS ABUSIVAS
}

\author{
María Elisa Morales Ortiz" \\ Universidad de la Frontera
}

\section{INTRODUCCIÓN}

Este trabajo pretende abordar una cuestión de Derecho inglés y por ello parece conveniente comenzar con una breve introducción a este sistema. Principalmente, porque el tema se inserta dentro del asunto más general de la protección al consumidor el cual se haido desarrollado en el Derecho inglés no de la típica forma que conocemos bajo la designación de Common Law sino que a través de legislación. Esto podría resultar, a primera vista, un tanto confuso. Es por dicha razón que primero se explica, brevemente, la relación entre Common Law y el Derecho inglés. Enseguida, se abordan las fuentes de Derecho inglés donde se hará re-

\footnotetext{
* Doctora en Derecho, Universidad de Chile; Licenciada en Ciencias Jurídicas y Sociales, Universidad Austral de Chile; Profesora de Derecho Civil y Comercial, Departamento de Ciencias Jurídicas, Facultad de Ciencias Jurídicas y Empresariales, Universidad de la Frontera, Temuco, Chile. Correo postal: Avenida Francisco Salazar 01145, Temuco. Correo electrónico: maria.morales@ufrontera.cl.El presente artículo ha sido financiado parcialmente por DIUFRO PROY.DI16-6003 y porbeca CONICYT de doctorado nacional número 21120410. Este trabajo es parte de mi tesis doctoral, titulada "Control preventivo de cláusulas abusivas en el ordenamiento jurídico chileno. Una propuesta de control fuerte".
}

ferencia, dentro de lo que resulte pertinente, al Derecho europeo y a la ley, para luego describir la evolución y reforma de dicho sistema en materia de cláusulas abusivas hasta llegar al Consumer Rights Act 2015, estableciendo un paralelo entre lo que regía antes y lo que rige actualmente.

\section{Algunas palabras SOBRE EL DERECHO INGLÉS \\ 1. El Common Law y el Derecho inglés}

En términos generales, se habla de Common Law como una familia o tradición jurídica, que encuentra su origen en el Derecho inglés, pero que trasciende fronteras ${ }^{1}$. Algunos de sus principales rasgos son su característico modo de pensar el derecho consistente en un desarrollo gradual del mismo a través de las decisiones de los tribunales. También se le atribuye un particular contexto, desarrollo histórico y siste-

${ }^{1}$ La familia del Common Law comprende la mayoría de los países de lengua inglesa y ha influenciado a todos los países que de alguna forma estuvieron vinculados o asociados políticamente con Inglaterra. DAVID \& JAUFFRET-SPINOSI (2010), p. 206. 
ma de fuentes ${ }^{2}$. A partir de lo último, los primeros comparatistas distinguieron Common Law de Civil Law -refiriéndose con este último al Derecho de Europa continental- donde justamente la más notable diferencia estuvo constituida por encontrarse el Derecho plasmado de manera principal en leyes o códigos en Europa continental, mientras que en Inglaterra se encontraba consagrado mayormente en las decisiones de los tribunales ${ }^{3}$.

En términos más específicos, dentro del contexto del Derecho inglés, Common Law puede ser visto de varias maneras. En primer lugar, como un conjunto de reglas y principios de creación judicial, en contraposición al derecho contenido en legislación. Esta acep ción se utiliza para hacer la diferencia entre dos fuentes del Derecho, que operan dentro de un mismo sistema legal. En este sentido, no se debe entender que el Common Law y la legislación son dos compartimentos estancos sin interacción, pues la tarea del abogado es integrar reglas desde esas diferentes fuentes de una manera coherente. En segundo lugar, se ha utilizado para distinguir el cuerpo de reglas creadas por los jueces de los tribunales superiores de las reglas de equity desarrolladas por la Court of Chancery ${ }^{4}$.

${ }^{2}$ Zweigert \& Kötz (1998), pp. 68-72.

${ }^{3}$ David (1980), p. 16. Aunque la denominación Civil Law, ha sido criticada, pues lo más adecuado para identificar la tradición es utilizar el epíteto romano-germánico elegido para darle el mérito a los esfuerzos comunes tanto de las universidades de los países latinos como de las de los países germánicos. DAVID Y JAUFFRET-SPINOSI (2010), p.15.

${ }^{4}$ El término 'equity'se refiere a un específico set de reglas legales. Aunque originalmente se inspiró en ideas de equidad, en la actualidad es
En tercer lugar, se habla de Common Law como fuente de principios generales del Derecho ${ }^{5}$.

En este trabajo se utilizarán las distintas acepciones del término common law. Cuál de ellas se usa en cada caso vendrá determinado por el contexto.

\section{Derecho inglés y sus fuentes}

El Reino Unido está conformado por Inglaterra, Gales, Escocia e Irlanda del Norte $^{6}$. En un sentido técnico, cuando se habla de Derecho inglés, en cuanto a su ámbito de validez territorial, se incluye a Inglaterra y Gales. En consecuencia, no quedan comprendidos Irlanda del Norte ni Escocia. Por lo tanto, cuando se habla de Derecho inglés técnicamente no se está haciendo alusión al Derecho de todo el Reino Unido. Sin embargo, esta es una concepción estricta, pues en un sentido más amplio la denominación se utiliza para designar a la universalidad de este mismo Derecho, considerado como un modelo para una gran parte de la humanidad, ${ }^{7}$ como sinónimo de Common Law en el sentido de familia o tradición jurídica. Cuando en lo que sigue se hable de Derecho inglés, se estará haciendo alusión a la primera concepción, como Derecho inglés en sentido estricto.

una particular rama o área del Derecho inglés que solo puede ser bien entendida si se atiende a su desarrollo histórico. Véase ZwEIgert y KötZ (1998), pp. 187-191; DAVID y JAUfFRETSPINOSI (2010), pp. 221-224.

${ }^{5}$ BeLL (2013), p. 10.

${ }^{6}$ Véase www.ons.gov.uk/ons/guidemethod/geography/beginner-s-guide/ administrative/the-countries-of-the-uk/index. html [fecha de consulta: 21 de abril de 2015].

${ }^{7}$ David y Jauffret-Spinosi (2010), p.207. 
En cuanto a las fuentes del Derecho inglés, John Bell las enumera de la siguiente forma ${ }^{8}$ : Derecho de la Unión Europea; La Convención Europea sobre Derechos Humanos; La Constitución; El Common Law; La ley (statutes y otros instrumentos legislativos); Precedentes $^{9}$ y la Costumbre.

Dado que la mayor parte de las disposiciones sobre protección al consumidor en el Derecho inglés están contenidas en legislación y, como se verá más adelante, una de las importantes normas sobre cláusulas abusivas consiste en la implementación de una directiva europea, a continuación solo se desarrollarán el Derecho de la Unión Europea y la legislación ${ }^{10}$.

\section{a) Derecho de la Unión Europea}

Reino Unido es miembro de la Unión Europea $^{11}$ desde $1973^{12}$. Con antelación, a través de la European Communities Act $1972^{13}$, se incorporó el Derecho de la Unión Europea como fuente del Derecho inglés, haciendo a los tratados emanados de esta organización

${ }^{8}$ BeLl (2013), p. 4.

${ }^{9}$ Una explicación del precedente, especialmente dirigida para juristas de otras tradiciones y traducida al español puede encontrarse en WHITTAKER (2008).

${ }^{10}$ Para revisar un análisis completo sobre las fuentes del Derecho inglés se puede consultar, entre otros: WALKER y otros (2011); WILSON, Rutherford, StOREy, Wortley (2014).

${ }^{11}$ Independiente del Brexit, la pertenencia del Reino Unido a la comunidad ha sido un factor importante en la evolución de la regulación de las cláusulas abusivas en dicho sistema.

${ }^{12}$ Véase http://europa.eu/about-eu/countries/member-countries/[fecha de consulta: 4 de abril de 2015]

${ }^{13}$ European Communities Act 1972. parte del Derecho Interno, autorizando la implementación de la futura legislación europea ${ }^{14}$.

En cuanto a las fuentes del Derecho de la Unión Europea, se distingue entre legislación primaria (Derecho Originario) y secundaria (Derecho Derivado). La legislación primaria está compuesta por los tratados que son la principal fuente del Derecho de la Unión Europea ${ }^{15}$. La legislación secundaria consiste en reglamentos, decisiones y directivas ${ }^{16}$. Según el impacto que estas fuentes tienen en el Derecho Interno de cada país miembro, se habla de aplicación directa y efecto directo. Que sean directamente aplicables significa que sus respectivas disposiciones, una vez en vigor, se convierten de inmediato en parte del Derecho del Estado miembro, sin la necesidad de un acto legislativo interno especial ${ }^{17}$. La directa aplicabilidad se puede predicar de las disposiciones de los tratados, de los reglamentos y de algunas decisiones. Las directivas no son directamente aplicables porque requieren implementación ${ }^{18}$.

El efecto directo ${ }^{19}$, por su parte, consiste en la creación de derechos y de-

${ }^{14}$ BeLl (2013), p. 4.

${ }^{15}$ Actualmente, dos son los principales tratados: el Tratado de la Unión Europea y el Tratado de Funcionamiento de la Unión Europea. También se encuentra en vigor el Tratado Constitutivo de la Comunidad Europea de Energía Atómica. Los diferentes tratados de la Unión Europea se pueden consultar en http://europa.eu/eu-law/decision-making/treaties/index es.htm [fecha de consulta: 23 de abril de 2015.]

${ }^{16}$ SLAPPER (2014), p. 180.

${ }^{17}$ Elliott y Quinn (2011), p. 97.

${ }^{18}$ Ibid.

${ }^{19}$ Para profundizar sobre el efecto directo, véase Weatherill (2012), pp. 112-113. 
beres en el Derecho Interno sin la intervención de la legislación nacional ${ }^{20}$. A su vez, este efecto se divide en horizontal y vertical. El horizontal crea derechos entre las personas y, el vertical, entre las personas y el Estado miembro' ${ }^{21}$. El efecto directo solo puede predicarse de aquellas disposiciones que son claras, incondicionadas, y que no dependen de la adopción de nuevas medidas por las autoridades europeas o internas ${ }^{22}$. Las disposiciones de los tratados, reglamentos y directivas tienen efecto directo en cuanto cumplen con los antedichos requisitos ${ }^{23}$.

Entre las diferentes fuentes de Derecho europeo, son las directivas las que han presentado un considerable desarrollo en el ámbito del Derecho de Consumo. De hecho, se ha dicho que el Derecho europeo de los contratos 284 versa primordialmente sobre materias de consumo y se encuentra contenido por regla general, en directivas ${ }^{24}$. Por lo anterior, es que a continuación no se desarrollan todas las fuentes del Derecho de la Unión Europea, sino solo las directivas.

\section{b) Directivas}

Una directiva es un acto legislativo de la Unión Europea que establece un objetivo o dirección política de acuerdo con el cual todos los Estados miembros deben adaptar su legislación interna ${ }^{25}$.

Las directivas, no tienen necesariamente aplicación general, solo son

${ }^{20}$ BELL (2013), p. 5.

${ }^{21}$ Elliott y Quinn (2011), p. 97.

${ }^{22}$ BeLl (2013), p. 5.

${ }^{23}$ Elliott y Quinn (2011), p. 97.

${ }^{24}$ Roppo (2011), p. 179.

${ }^{25}$ BeLL (2013), p. 4. vinculantes para aquellos Estados a los cuales van dirigidas (aunque normalmente van dirigidas a todos los Estados miembros). Además, no son vinculantes en su totalidad sino solo en cuanto al resultado que deba conseguirse, instruyendo a los Estados respecto de ciertos objetivos, pero no respecto de cómo deberían conseguirlos. Asimismo, el Estado miembro debe implementar las disposiciones de la directiva en el Derecho interno, razón por la cual no son aplicables en forma directa ${ }^{26}$.

En cuanto al efecto de sus disposiciones en el Derecho del Estado miembro, las directivas no tendrán efecto directo horizontal hasta que sean implementadas como parte de la legislación nacional, pero sí pueden tener efecto directo vertical, lo que permite a las personas invocar la directiva en un tribunal nacional en contra del respectivo Estado, en el caso de no ser implementadas a tiempo.

Respecto de la implementación de una directiva en el Derecho Interno el Estado miembro tiene un específico plazo que varía de directiva en directiva, dependiendo de la dificultad que conlleve alcanzar los resultados requeridos, siendo el promedio de tiempo de dos años. Los Estados miembros deben implementar las directivas de la forma legalmente imperante en el Derecho Interno, por ejemplo, en el Reino Unido será a través de una ley o de alguna forma de legislación delegada ${ }^{27}$.

En el ámbito de la protección al consumidor se pueden nombrar varias

\footnotetext{
${ }^{26}$ Wilson, Rutherford, StOREy ANd WorTLEY, (2014), p. 187.

${ }_{27}$ Ibid.
} 
directivas, por ejemplo: directiva 1999/ 44/CE sobre determinados aspectos de la venta y las garantías de los bienes de consumo, directiva 2006/114/ CE sobre publicidad engañosa y publicidad comparativa, directiva 2011/ 83 sobre los derechos de los consumidores. En materia de cláusulas abusivas, el instrumento pertinente es la directiva 1993/13/CEE de 5 de abril de 1993, sobre las cláusulas abusivas en los contratos celebrados con consumidores.

Según Aristides Hatzis, la directiva 93/13 tiene entre sus objetivos básicos: proteger a los consumidores del detrimento de las cláusulas abusivas insertas en los contratos no negociados; hacer una lista de ejemplos de cláusulas abusivas que son comunes en ese tipo de contratos, y evitar la lesión de los intereses de los consumidores instando a los Estados para que presionen a los proveedores en orden a que no incluyan este tipo de cláusulas en sus contratos, creando así no solo un ambiente seguro para los consumidores sino, también, un sentimiento de seguridad de las transacciones para los proveedores ${ }^{28 .}$

Cuando esta norma se adoptó -5 de abril de 1993- varios Estados miembros ya contaban con regulación en orden a eliminar las cláusulas abusivas, fundamentalmente en el ámbito de los contratos de adhesión. En razón de esto se les reconoció a todos los Estados miembros la facultad de mantener las normas existentes o adoptar nuevas normas más estrictas en el contexto de lo que se conoce como armonización

\footnotetext{
${ }^{28}$ Hatzis (2008), p. 44.
}

mínima $^{29}$. La armonización mínima está establecida en el art. 8 de la directiva $93 / 13^{30}$. Esta fórmula ha sido criticada por poner en peligro el objetivo de lograr condiciones de mercado similares en toda Europa. Por otro lado, si bien podría garantizar a los consumidores un nivel mínimo de protección, desde el punto de vista de los comerciantes el hecho de que las disparidades puedan permanecer en gran medida, implicaría que aún no sería posible usar el mismo modelo de contrato en toda la Unión Europea $^{31}$.En cuanto a la forma en que la directiva regula las cláusulas abusivas, a continuación se señalan algunos de los más importantes aspectos ${ }^{32}$.

En lo que al ámbito de aplicación respecta, existe una doble limitación, objetiva y subjetiva, en tanto solo cubre cláusulas no negociadas individualmente en contratos celebrados entre profesionales y consumidores ${ }^{33}$. Esta restricción objetiva no parece ser tan relevante porque donde hay negociación normalmente no debería haber abuso, es más bien el ámbito de las cláusulas predispuestas donde las asimetrías que caracterizan al Derecho de Consumo se profundizan. Por otro lado, la gran mayoría de los términos

${ }^{29}$ Carballo (2013), pp. 21-22.

${ }^{30} \mathrm{El}$ citado artículo dispone: "Los Estados miembros podrán adoptar o mantener en el ámbito regulado por la presente Directiva, disposiciones más estrictas que sean compatibles con el Tratado, con el fin de garantizar al consumidor un mayor nivel de protección”. Sobre el debate sobre mínima y máxima armonización véase Howells (2002), pp. 73-80.

${ }^{31}$ Nebbia (2007), p. 9.

${ }^{32}$ Un desarrollo al respecto se puede ver en Carballo (2013), pp. 21-40.

${ }^{33}$ Carballo (2013), p. 23. 
contractuales negociados correspondería a la determinación del objeto o del precio, materias que, como se verá, la directiva excluye del test de abusividad.

Respecto de la determinación de qué cláusulas se considerarán abusivas, la directiva establece una noción general en su articulado y una lista meramente indicativa de cláusulas que pueden ser declaradas abusivas contenida en un anexo. La noción general se establece en el art. 3.1 en los siguientes términos:

"Las cláusulas contractuales que no se hayan negociado individualmente se considerarán abusivas si, pese a las exigencias de la buena fe, causan en detrimento del consumidor un tre los derechos y obligaciones de las partes que se derivan del contrato" 34 .

La directiva, además, encomienda a los Estados miembros la tarea de velar para que no se incluyan cláusulas abusivas en los contratos celebrados con consumidores, a través de lo establecido en los arts. 6 y 7.

En cumplimiento de dicho mandato, en el derecho inglés se dictó la

${ }^{34}$ La referencia a la buena fe es algo nuevo para los abogados ingleses, ya que esta nunca ha representado un papel explícito en el Derecho inglés de los contratos. La importancia de esto podría radicar en el impacto potencialmente innovador. Sin embargo, con lo interesante que este tema puede resultar, excede de los objetivos de este trabajo, por lo que no me detendré aquí. Para dichos efectos véase Zimmermann and Whittaker (2000); Brownsword, Hird and Howells (1999).
UTCCR $1994^{35}$, reemplazada por la de $1999^{36}$, que tuvo por objetivo la transposición de la directiva 93/13. El problema que esto trajo fue que lejos de convertirse en una regulación accesible, en aras de la protección al consumidor, complejizó el escenario en tanto ya existía una regulación al respecto la cual no fue derogada al momento de que UTCCR entró en vigencia, produciéndose un fenómeno de superposición de normas. Esta situación se revisará en extenso más adelante ${ }^{37}$.

\section{c) La ley (statutes)}

Como ya se dijo, a diferencia de lo que pasa con la regulación de los contratos, en general regidos por el Common Law, la mayoría de la regulación relativa a protección del consumidor en el Derecho inglés se encuentra contenida en leyes.

Lo anterior se justifica, en parte, por el conflicto entre la idea de protección de la parte débil y las raíces del Derecho de Contratos conforme a las cuales cada parte debería proteger sus propios intereses al momento de contratar. Otras razones se pueden esgrimir. Por ejemplo, el hecho de que ciertas sanciones que requieren estar establecidas por la ley hayan sido vistas como la única forma para hacer frente a ciertas prácticas comerciales relacionadas con la protección al consumidor. Por otro lado, solo los tribunales superiores están realmente involucrados en el desarrollo del Common Law y los asuntos de Derecho de Consumo rara

\footnotetext{
${ }^{35}$ UTCCR 1994.

${ }^{36}$ UTCCR 1999.

${ }^{37}$ Véase 3. a)
} 
vez llega a esas instancias. Aquellos casos que llegan a judicializarse tienden a ser tratados en los tribunales inferiores, por lo que hay muy pocas posibilidades de sentar nuevo precedente. Además, las asociaciones de consumidores han representado un importante papel, ejerciendo presión para la reforma del Derecho. En ese sentido, una de sus más importantes herramientas ha sido la publicación de sus opiniones con lo que no logran presionar directamente a los tribunales, pero sí al gobierno por cambios en la legislación ${ }^{38}$.

Entonces, es la legislación la principal fuente en asuntos de protección al consumidor. Pero antes de ir al desarrollo de la ley como fuente del Derecho inglés, conviene aclarar algunos puntos. En primer lugar, las reglas de Common Lare $^{39}$ relativas al Derecho de los Contratos resultan aplicables a todos los contratos. El hecho de que en las últimas décadas la intervención del Parlamento haya aumentado considerablemente en ciertas áreas, como, por ejemplo, en el ámbito de los contratos de trabajo o de consumo, trae como efecto que estos se encuentran ahora cubiertos por normas especiales que regulan la forma en que se celebran y las cláusulas que pueden contener ${ }^{40}$. Se trata, porlotanto, de unasunto de especialidad, donde las fuentes legisladas tienen preferencia de aplica-

${ }^{38}$ Elliott y Quinn (2011), pp. 404-405.

${ }^{39}$ Se está haciendo referencia a reglas o doctrinas establecidas por decisiones judiciales (Case Law), en este sentido se habla Common Law en tanto principal fuente del Derecho. Un ejemplo de una regla de Common Law relativa al Derecho de Contratos es la offer and acceptance. Op. cit., p. 12.

${ }^{40}$ Op. cit., p. 386. ción por sobre la fuentes no legisladas en caso de abordar la misma materia. Esto no quiere decir que en estos casos la regla de Common Law sea abolida, ya que este es el Derecho Común, sino que son excluidas dando paso a las disposiciones legislativas que en el caso de abordar alguna materia, se aplican especialmente $^{41}$. En segundo lugar, cabe hacer presente que antes de que comiencen a regir las primeras leyes sobre cláusulas abusivas, el Common Law ya había desarrollado mecanismos de revisión de contratos de adhesión, de acuerdo con los cuales la respectiva cláusula podría formar parte del contrato si se le ha dado a la otra parte la oportunidad razonable de familiarizarse con aquella, en lo que se conoce como reasonable notice test ${ }^{42}$. También se ha usado la regla contra proferetem, de conformidad a la cual las cláusulas ambiguas son interpretadas en contra de los intereses del vendedor o proveedor que las redactó ${ }^{43}$.

\section{d) Las leyes y la legislación delegada}

Una ley o statute, propiamente tal, es un Act of Parliament. Sin embargo, existen otras formas de legislación que es posible agrupar dentro de la designación "legislación delegada".

John Bell ${ }^{44}$, al hablar de las fuentes, sostiene que las leyes y otras formas de legislación son la parte más subs-

${ }^{41}$ Cartwright (2013), p. 17.

${ }^{42}$ Ebers (2008), p. 220. Aunque se ha dicho que este es un muy básico requerimiento de transparencia porque no se exige que la cláusula sea accesible, en cuanto al tamaño de la letra y al lenguaje utilizado. WiLlet (1997), p. 224.

${ }^{43}$ Willet (1997), p. 225.

${ }^{44}$ BELL (2013), p. 12. 
tancial del Derecho inglés, esgrimiendo que muchas de las principales bases de varias ramas del Derecho han sido especialmente creadas por leyes, poniendo como ejemplo el Derecho Comercial (rama dentro de la cual se suele incluir el Derecho de Consumo). $\mathrm{El}$ autor señala que una típica ley se divide en secciones, algunas de las cuales se dividen en subsecciones y apéndices o anexos (schedules). Usualmente contienen también secciones de interpretación las cuales definen ciertos términos clave utilizados en la respectiva ley. Y la ley autoriza la adopción de legislación delegada, para una regulación más detallada.

La legislación delegada consiste en un vasto cuerpo de reglas, reglamentos, órdenes y ordenanzas que, dependiendo del órgano que los elabora, se deno288 minan: orders in council, by-lawes statu tory instrument.

Las Orders in Council, formalmente son elaboradas por el departamento gubernamental pertinente, aprobado por el Consejo Privado (Privy council) ${ }^{45}$ y firmados por la Reina. Las by-laws son elaboradas por autoridades locales y tienen que ser aprobadas por el gobierno central. Por último, los Statutory instrument son elaborados por ministros de gobierno $^{46}$.

La legislación delegada requiere de una ley habilitante, que puede ser es-

${ }^{45}$ El Consejo Privado es uno de los órganos más antiguos del gobierno. Está integrado, entre otros, por ministros de Estado, el Presidente, los líderes de los principales partidos políticos. Su principal función es asesorar a la Reina. Mas sobre este órgano en http://privycouncil.independent.gov.uk/privy-council/ [Fecha de consulta: 5 de mayo de 2015].

${ }^{46}$ Elliott y Quinn (2011), p. 75. pecífica, dando un poder limitado para regular un tema especial o, bastante general, permitiendo un amplio rango de regulación, tal como se encuentra dispuesto en el European Communities Act 1972, sección número 2, el cual faculta al ejecutivo para elaborar la legislación que se requiera con el objetivo de implementar en el Derecho Interno la legislación europea que resulte pertinente $^{47}$.

Ejemplo de lo último fue la UTC$\mathrm{CR}$, statutory instrument, que precisamente señalaba que su elaboración obedecía al ejercicio de las facultades establecidas en la sección número 2 (2) del European Communities Act 1972. Cabe agregar que el método usual por el cual se implementan directivas en el Derecho inglés es a través de statutories instruments, sin embargo, también se suele recurrir a los Acts of Parliament como, por ejemplo, el reciente CRA $2015^{48}$.

\section{Regulación DE CLÁUSULAS ABUSIVAS EN EL DERECHO INGLÉS}

Desde la década de 1960, el Parlamento inglés ha aprobado una serie de leyes destinadas a dar protección a los consumidores. Solo por nombrar algunas: Consumer Protection Act 1961; Trade Descriptions Act 1968; Consumer Credit Act 1974; Consumer Safety Act 1978 and the Consumer Safety (Amendment) Act 1986; Sale of Goods Act 1979; Supply of Goods and Services Act 1982 y Sale and Supply of Goods Act 1994.

${ }^{47}$ Elliott y Quinn (2011), p. 75.

${ }^{48}$ CRA 2015. 
En materia de cláusulas abusivas, en 1977 se dictó la UCTA ${ }^{49}$, norma que en 1994 vio parte de su campo de aplicación invadido por otra norma. En efecto, la directiva 93/13 fue implementada en Reino Unido inicialmente por el UTCCR de 1994. Esta fue revocada y reemplazada luego por el UTCCR 1999. Como se dijo, antes de la entrada en vigencia de la UTCCR ya existía un instrumento que regulaba en parte el tema de las cláusulas abusivas, UCTA. El problema se genera en tanto UTCCR no tuvo entre sus objetivos reformar ni revocar la regulación prexistente, por lo que ambos estuvieron vigentes por años regulando, en gran medida, las mismas materias.

Con la coexistencia de estos dos instrumentos se produjo un problema de superposición normativa, que tiene su origen en la forma en que UTCCR implementó la directiva 93/13. La trasposición de esta directiva en el Derecho inglés por UTCCR fue un "fracaso institucional" ${ }^{50}$, descrito como una situación en que las jurisdicciones copian las directivas de manera que la nueva legislación es superpuesta a la anterior en vez de adaptar el Derecho Interno de manera que pueda calzar con los requerimientos de la respectiva directiva.

Este escenario, desde luego, fue objeto de críticas ${ }^{51}$, ya que implementar una directiva a través de la copia directa, sin una adaptación al Derecho vigente, puede resultar aceptable en

${ }^{49}$ UCTA 1977.

${ }^{50}$ Beale (2006), p. 31.

${ }^{51}$ Parte de estas críticas se pueden revisar en Hondius (1997). aquellos casos donde la materia específica no se encuentra regulada en el Derecho Interno o cuando este último es muy similar a la directiva ${ }^{52}$. La situación, debatida por más de una década, se ha intentado superar con una nueva ley, CRA 2015, que reemplaza parcialmente al UCTA y totalmente a la UTCCR, convirtiéndose en el nuevo instrumento legal que implementa la directiva 93/13. Sin embargo, antes de examinar esta última, conviene abordar el conflicto normativo ya aludido para entender la evolución normativa en el ámbito del control de las cláusulas abusivas.

\section{El conflicto normativo entre UTCCR y UCTA}

Una buena forma de aproximarse a este tema, es revisando los informes de la Law Commission. La Law Commis$\operatorname{sion}^{53}$ es un órgano independiente, integrado por la English Law Commission y la Scottish Law Commission, creado por la Law Commissions Act $1965^{54}$ para mantener el Derecho bajo revisión y recomendar reformas si esto es necesario.

En 2001 el Department of Trade and Industry ${ }^{55}$ pidió a la Law Commission una nueva redacción del Derecho sobre cláusulas abusivas, en un solo

${ }^{52}$ Beale (2006), p. 32.

${ }^{53}$ Véase http://lawcommission.justice.gov. uk/[fecha de consulta: 19 de marzo de 2015].

${ }^{54}$ Law Commissions Act 1965.

${ }^{55}$ El DTI fue un departamento del gobierno de Reino Unido. Este fue reemplazado con la creación del Department for Business, Enterprise and Regulatory Reform y el Department for Innovation, Universities and Skills en junio de 2007. 
cuerpo de legislación, que unifique el Derecho existente, con un lenguaje más claro y accesible, además de solicitarle una referencia a la protección legal de los pequeños empresarios. En respuesta a dicha petición, el 7 de agosto de 2002 la Comisión publicó un informe denominado Unfair Terms in Contracts. A Join Consultation Paper ${ }^{56}$. Una revisión del instrumento resulta ineludible y la razón de ello, en palabras de Hugh Beale:

"El origen del proyecto radica en la historia de la legislación sobre las cláusulas abusivas en el Reino Unido. Esto se describe brevemente en el Consultation Paper ${ }^{\prime 57}$.

El reporte final al respecto, fue pu290 blicado en febrero de 2005, el cual contiene, además, un anteproyecto de ley ${ }^{58}$.

En ambos instrumentos la Law Commission se refiere a la existencia en el Derecho inglés de dos piezas de legislación relativas a cláusulas abusivas, el UCTA y la UTCCR, confron-

${ }^{56}$ Law Commission. Unfair Terms in Contracts. AJoint Consultation Paper. (Law Com Consultation Paper $N^{\circ} 166$, Scott Law Com Discussion Paper No 199), 2002.

57 "The origin of the project lies in the history of unfair terms legislation in the UK. This is described briefly in the Consultation Paper". BeAle (2004), p. 290. La traducción es propia.

${ }^{58}$ Law Commission. Unfair Terms in Contracts. Report on a reference under section 3(1) (e) of the Law Commissions Act 1965. The Law Commission (LAW COM No 292). The Scottish Law Commission (SCOT LAW COM No 199), 2005. La sección 3(1) de la Law Commission Act, se refiere a la atribución de la Comisión para presentar informes como propuesta de reforma para cualquier rama del Derecho. tándolas y haciendo patente sus inconsistencias, para finalmente dar a conocer su propuesta de reforma. Entre dichas diferencias, a continuación se mencionan algunas.

El UCTA se enfocaba principalmente en cláusulas de exención o restricción de responsabilidad y era aplicable tanto a contratos de consumo como a otros contratos ${ }^{59}$. Además, se aplicaba a cláusulas negociadas y a cláusulas predispuestas. En cuanto a los efectos de su aplicación, podía producir la ineficacia inmediata de la cláusula respectiva o la nulidad, a menos que se demostrase que la cláusula era razonable. Aunque el ámbito de aplicación parecía bastante amplio, UCTA no resultaba aplicable a todos los tipos de cláusulas, solo a cláusulas de exención o restricción de responsabilidad $^{60}$ de modo que, por ejemplo, las cláusulas que buscan aumentar las obligaciones o la responsabilidad de una de las partes quedaban fuera de su ámbito de aplicación ${ }^{61}$.

Por su parte, UTCCR se aplicaba a un amplio rango de cláusulas contractuales, pero dentro del ámbito de los

${ }^{59}$ La mayoría de las secciones se aplican tanto a contratos de consumo como a los que no revisten esa calidad, salvo la sección 4 y 5 , Part I, UCTA, que se aplica solo a contratos de consumo.

${ }^{60}$ Las cláusulas de indemnización en contratos de consumo, también quedan comprendidas. Un consumidor no puede, bajo esta regulación, por referencia a alguna cláusula contractual ser obligado a indemnizar a otra con respecto a la responsabilidad que pueda haber incurrido por la negligencia o incumplimiento contractual de esta última. Véase Parte I, sección 4, UCTA.

${ }^{61}$ Por ejemplo, una cláusula que permita al proveedor aumentar el precio a pagar. BEALE (2004), p. 289. 
contratos celebrados entre proveedores y consumidores ${ }^{62}$. De la misma forma que lo dispone la directiva 93/13, no quedaban incluidas las cláusulas referidas a la adecuación entre el precio y los bienes o servicios ni al objeto principal del contrato, en la medida en que estuviesen redactadas en forma clara ${ }^{63}$.

Los conceptos y definiciones que estas dos legislaciones empleaban eran diferentes. Por ejemplo, bajo UCTA se consideraba consumidor quien hubiese celebrado el contrato fuera del curso de su negocio teniendo como contraparte a quien estaba contratando dentro de su giro ${ }^{64}$, pudiendo ser, incluso, una empresa siempre que se tratare de una transacción no habitual y accesoria a su negocio o actividad empresarial ${ }^{65}$. En cambio, bajo UTCCR era consumidor la persona natural que

${ }^{62}$ De conformidad a la sección 4 de la UTC$\mathrm{CR}$, esta resulta aplicable a cláusulas abusivas en contratos concluidos entre un vendedor o proveedor y un consumidor.

${ }^{63}$ UTCCR, sección 6(2).

${ }^{64}$ UCTA, sección 12.

${ }^{65} \mathrm{R} \&$ B Customs Brokers Co Ltd v United Dominions Trust Ltd (1988). En resumen, R\&B -empresa demandante dedicada al negocio de transporte de carga y agencia marítima-compró un automóvil usado a la empresa demandada para el uso de uno de sus directores. Existía en el contrato de compraventa respectivo una cláusula que excluía su responsabilidad por garantía, estableciendo que dicho término no afectaría a quienes son considerados consumidores bajo UCTA. Tiempo después, el vehículo sufre un desperfecto en el techo. $\mathrm{R} \& \mathrm{~B}$ demandó indemnización de perjuicios argumentando que esto era contrario a UCTA 1977 sección 6, y United Dominios sostuvo que el R \& B no podían acogerse a esta ley ya que como se trata de una empresa no puede ser considerado consumidor. En este caso la empresa demandante fue considerada como un consumidor ya que se trató de una operación incidental fuera del curso del negocio de la empresa. actúa con un propósito ajeno a su negocio, empresa o profesión ${ }^{66}$. También ocurría respecto de la definición de proveedor (contraparte del consumidor en el contrato de consumo) ${ }^{67} \mathrm{de}$ signado en UCTA bajo el término ' $b u$ siness' el cual incluía tanto actividades profesionales como las actividades de cualquier departamento de gobierno ${ }^{68}$ y en UTCCR bajo la designación seller or supplier la cual se refería a toda persona natural o jurídica, ya sea pública o privada, que en contratos cubiertos por UTCCR, hubiere estado actuando con propósitos relacionados a su negocio, empresa o profesión ${ }^{69}$.

Para evaluar la abusividad de una cláusula se establecían distintas fórmulas. En UCTA las cláusulas quedaban sometidas a un test de razonabilidad (reasonableness), mientras que bajo la regulación de UTCCR eran válidas únicamente al superar el test de equidad o justicia (assessment of fairness $)^{70}$. El test de razonabilidad se refería a requerimientos de justicia en la in-

${ }^{66}$ UTCCR, sección 3(1).

${ }^{67}$ Se hace esta aclaración, de que cuando se habla de proveedor se está haciendo referencia a la contraparte del consumidor en el contrato de consumo, porque las distintas leyes a las que se hace referencia aquí utilizan distintas designaciones, cuestión terminológica sobre lo cual no me detendré considerándolos a todos dentro del término "proveedor".

${ }^{68}$ UCTA, sección 14.

${ }^{69}$ UTCCR, sección 3(1).

${ }^{70}$ Véase sección 6 Assessment of unfair terms. Según esta sección, el carácter abusivo de una cláusula contractual se evaluará teniendo en cuenta la naturaleza de los bienes o servicios por los cuales el contrato fue concluido, el momento de la celebración del mismo, las circunstancias que concurran en su celebración, así como todas las demás cláusulas del contrato, o de otro contrato del cual dependa. 
clusión de una cláusula y proveía una guía para su aplicación ${ }^{71}$. Por su parte, el test de equidad o justicia de una cláusula no proveía una guía de aplicación, pero en su lugar establece algunas reglas ${ }^{72}$, por ejemplo, a través de la definición de cláusula abusiva que establece ciertos elementos que se deberían reconocer durante la evaluación de la cláusula respectiva:

"Una cláusula contractual que no se hayan negociado individualmente se considerará abusiva si, pese a las exigencias de la buena fe, causa un desequilibrio importante entre los derechos y obligaciones de las partes que se derivan del contrato, en detrimento del consumidor"73.

292
En relación con lo anterior también era distinta la regulación referida a la carga de la prueba. Bajo UCTA era el proveedor quien debía demostrar que una cláusula se ajustaba al requerimiento de razonabilidad ${ }^{74}$, en tanto que en UTCCR no se especificaba quién debía demostrar la justicia o equidad de una cláusula.

${ }^{71}$ Respecto de The reasonableness testen UCTA, véanse secciones 11, 24 y el cuadro 2 que contiene una guía para su aplicación. Este test se refiere a requerimientos de justicia y razonabilidad en la inclusión de la cláusula.

${ }^{72}$ UTCCR, sección 5 y 6.

${ }^{73}$ UTCCR, sección 5 (1) "A contractual term which has not been individually negotiated shall be regarded as unfair if, contrary to the requirement of good faith, it causes a significant imbalance in the parties' rights and obligations arising under the contract, to the detriment of the consumer". La traducción es propia.

${ }^{74}$ UCTA, sección 11(5).
Otra diferencia importante entre UCTA y UCCTR, era que la primera contenía dos partes, una primera parte aplicable a Inglaterra, Gales e Irlanda del Norte y una segunda aplicable solo a Escocia, y algunas disposiciones comunes a todo el Reino Unido ${ }^{75}$; por su parte, que la segunda no distinguía al respecto y se aplicaba a todo el Reino Unido.

Hay ciertos aspectos que en UCTA no estaban previstos y que se incorporaronporUTCCR.Porejemplo,UTCCR introdujo el principio de transparencia al contemplar que las cláusulas de un contrato deben expresarse de manera clara y comprensible ${ }^{76}$. Además, incorporó un anexo con una lista ejemplar no exhaustiva de cláusulas que podrían ser declaradas abusivas ${ }^{77}$. Otro importante punto, es que esta regulación permitía a la $\mathrm{OFT}^{78}$, y a otros organismos, recurrir al juez para prevenir que cláusulas abusivas sean usadas. Se trata de una potestad preventiva de control de cláusulas abusivas.

Así, la coexistencia de dos regímenes, ambos aplicables a cláusulas abusivas, pero con distinta extensión en cuanto a sus respectivos ámbitos, trajo consigo la superposición parcial, empleando términos y conceptos diferentes, dando distinto tratamiento a situaciones similares ${ }^{79}$.

${ }^{75}$ UCTA Parte I, Parte II y Parte III, respectivamente.

${ }^{76}$ UTCCR, sección 7(1).

${ }^{77}$ UTCCR, anexo 2.

${ }^{78}$ OFT: órgano actualmente disuelto el 1 de abril de 2014. A la fecha de la publicación del informe en comento, la OFT era el principal órgano responsable de la protección de los intereses del consumidor en todo Reino Unido.

${ }^{79}$ Algunas cláusulas que eran válidas, en principio, bajo UTCCR, no producían efecto alguno bajo la UCTA, por ejemplo, las cláu- 
Esta superposición complicó la interpretación y aplicación de las respectivas normas. De hecho, el Department of Trade and Industry del Reino Unido recibió quejas provenientes del sector de los empresarios y de grupos de consumidores sobre las dificultades causadas por la existencia de dos regímenes $^{80}$. Por un lado, UCTA, escrita en un estilo denso, el cual resultaba difícil de seguir, incluso, para abogados especialistas y, por otro lado, UTCCR que utilizaba términos y conceptos europeos que no eran familiares para los abogados ingleses. En resumen, la combinación de estas dos legislaciones, trajo una confusión generalizada para consumidores, proveedores y sus asesores legales ${ }^{81}$.

La propuesta de la Law Commission fue simplificar la legislación existente, combinando ambas regulaciones en un solo instrumento legal aplicable a todo el Reino Unido, manteniendo el nivel de protección sobre estos últimos, pretendiendo igualar hacia arriba las diferencias entre UCTA y UTCCR ${ }^{82}$.

En resumen, el anteproyecto propuso lo siguiente. En relación con los contratos de consumo, planteó extender el ámbito de aplicación en los términos de la UTCCR, continuar privando de efecto a las cláusulas que limitan la responsabilidad por muerte o lesiones corporales o aquellas que excluyen las

sulas que limitan la responsabilidad por muerte o lesiones corporales o aquellas que excluyen las obligaciones básicas relativas a la calidad e idoneidad de los bienes

${ }^{80}$ BeAle (2004), p. 290.

${ }^{81}$ Law Commission. Unfair Terms in Contracts (LC NO 298; SLC NO 199) Summary, p. 1.

${ }^{82}$ Op. cit., p. 2. obligaciones básicas relativas a la calidad e idoneidad de los bienes, incluir cláusulas negociadas y cláusulas predispuestas y , siguiendo a UCTA ${ }^{83}$, establecer que la carga de la prueba para demostrar que una cláusula es justa recae sobre el proveedor. En el caso de los organismos con facultades preventivas, estos deberán demostrar que la cláusula es abusiva ${ }^{84}$,En cuanto a los contratos $\mathrm{B}_{2} \mathrm{~B}^{85}$, se propuso la protección para los pequeños empresarios ${ }^{86}$. Sin embargo, en este caso, el control sobrelas cláusulas solo se aplicaría sobre aquellas no negociadas ${ }^{87}$ sin contemplar para

${ }^{83}$ Véanse secciones 11(5) y 24(4), UCTA. UTCCR no establece quien debe soportar la carga de la prueba, salvo para el caso en que el proveedor que reclama que la cláusula fue individualmente negociada, él mismo debe demostrarlo [sección 5(4)]

${ }^{84}$ Law Commission. Unfair Terms in Contracts (LC NO 298; SLC NO 199) Summary, p. 2.

${ }^{85}$ UTCCR solo se aplica a contratos de consumo. Por su parte, UCTA resulta aplicable tanto a contratos celebrados entre un proveedor y un consumidor como a contratos celebrados entre proveedores. Sin embargo, reciben un tratamiento diferente. Por ejemplo, las cláusulas de exclusión o restricción de responsabilidad no producen efecto alguno en contratos de consumo, mientras que en contratos entre proveedores las cláusulas se someten al test de razonabilidad (secciones 6, 7, 20 y 21). En el caso de las secciones 3 y 17, si se trata de contratos entre consumidores se aplica tanto a cláusulas negociadas o predispuestas, más si se trata de contrato entre proveedores, su aplicación se reduce solo a cláusulas no negociadas.

${ }^{86}$ La Comisión ha definido a los pequeños empresarios como aquellos con nueve o menos empleados. Law Commission. Unfair Terms in Contracts. Report on a reference under section 3(1)(e) of the Law Commissions Act 1965. The Law Commission (LAW COM No 292). The Scottish Law Commission (SCOT LAW COM No 199), 2005, p. 78.

${ }^{87}$ Law Commission. Unfair Terms in Contracts (LC NO 298; SLC NO 199) Summary, p. 2. 
estos contratos el control preventivo de cláusulas en favor de los pequeños empresarios, pues considera que no existe un organismo con los recursos suficientes para asumir dicha tarea ${ }^{88}$. Además, se estableció una serie de excepciones para no interferir en el flujo contractual que se encuentra regulado o en caso de que el proveedor sea suficientemente sofisticado como para velar porsus propiosintereses. Por ejemplo, excluyendo contratos por servicios financieros, contratos sobre $£ 500.000$, o casos en que el pequeño empresario aparece asociado con otros empresarios ${ }^{89}$.

En mayo de 2012, el BIS ${ }^{90}$, pidió a la Comisión una actualización del informe redactado en 2002. En respuesta a esta solicitud, la Comisión publicó una serie de instrumentos ${ }^{91}$ que culminaron en marzo de 2013 con un docu294 mento denominado Unfair Terms in Consumer Contracts: Advice to the Department for Business, Innovation and Skills ${ }^{92}$. En-

${ }^{88}$ No obstante que, para la Comisión, dicha protección sería útil, ya que muchas pequeñas empresas no cuentan con la capacidad parallevar una acción judicial.

${ }^{89}$ Law Commission. Unfair Terms in Contracts (LC NO 298; SLC NO 199) Summary, p. 3.

${ }^{90} \mathrm{El} \mathrm{BIS}$ fue un departamento de gobierno de Reino Unido, encargado de fomentar el crecimiento económico de dicho país. En julio de 2016 fue reemplazado por el Department for Business, Energy \& Industrial Strategy.

${ }^{91}$ Unfair Terms in Consumer Contracts. Impact Assessment; Unfair Terms in Consumer Contracts: A New Approach? Summary of the Issues Paper; Unfair Terms in Consumer Contracts: A New Approach? Appendices A to D of Issues Paper; Unfair Terms in Consumer Contracts: A New Approach? Issues Paper A Joint Issues Paper.

${ }_{92}$ Unfair Terms in Consumer Contracts: Advice to the Department for Business, Innovation and Skills; Unfair Terms in Consumer Contracts: Advice to the Department for $\mathrm{Bu}^{-}$ siness, Innovation and Skills Summary. tre los distintos aspectos que aquí se abordaron, seguramente el más importante tienen relación con la definición del objeto principal del contrato y la adecuación del precio como elementos excluidos de la apreciación de abusividad de una cláusula ${ }^{93}$. La Comisión recomendó una reforma en este sentido, ya que la incertidumbre de dichos términos puede afectar tanto a consumidores como a proveedores. En concreto, dichas cláusulas quedarían excluidas de revisión si son transparentes y notorias (prominent). Según la Comisión hay transparencia si la cláusula se expresa en términos claros y comprensibles, fácilmente disponibles y legibles. Todas las cláusulas de un contrato deben ser transparentes, y si no es así entonces los organismos competentes pueden impugnarla. Una cláusula es notoria si esta se presenta en términos tales que un consumidor promedio puede darse cuenta o estar consciente de ella. Mientras más onerosa e inusual es una cláusula, más notoriedad necesita. No todas las cláusulas pueden ser notorias, y que una cláusula no lo sea no significa que sea abusiva ni hace surgir una presunción en su contra, pero sí puede ser objeto de test de equidad o justicia. De conformidad a lo anterior, se propuso la siguiente norma:

"No se hará evaluación de justicia o equidad,

(A) de una cláusula que especifique el objeto principal del contrato; o

${ }^{93}$ Contenido en el art. 4(2) de la directiva 93/13 y en el 6(2) de la UTCCR. BIS había solicitado un especial pronunciamiento al respecto. 
(B) el precio, en comparación con los bienes o servicios suministrados a cambio, siempre que la cláusula en cuestión sea transparente y notoria" 94 .

En cuanto a la lista gris indicativa de cláusulas que podrían ser declaradas abusivas, contenida en UTCCR (Schedule 2) y que reproduce la lista contenida en el anexo de la directiva 93/13, la Comisión sugirió que la nueva legislación mantenga dicha lista con algunas adiciones.

También se recomendó replicar las disposiciones de UCTA que privan de efecto a aquellas cláusulas que pretenden excluir la responsabilidad del proveedor por muerte o lesiones, las que siempre deberían ser consideradas abusivas, en el criterio de la Comisión. El informe sigue a UCTA también, al plantear que el campo de protección se debería ampliar a cláusulas negociadas, lo cual, por un lado, no afectaría a demasiadas cláusulas, ya que normalmente las cláusulas negociadas caerán dentro del campo de excepción del precio u objeto principal, pero haría la ley más simple al abolir la distinción entre cláusulas negociadas y no negociadas.

Por otro lado, se aconsejó mantener los términos de la directiva 93/13 relativos a la evaluación de abusividad de las cláusulas (fairness test), reempla-

94 "No assessment of fairness shall be made (a) of a term which specifies the main subject matter of the contract; or (b) of the amount of the price, as against the goods or services supplied in exchange, provided that the term in question is transparent and prominent". Unfair Terms in Consumer Contracts: Advice to the Department for Business, Innovation and Skills, p. 35. La traducción es propia. zando al test de razonabilidad de UCTA que, aunque se reconocía una gran similitud entre ambos, se prefirió dar lugar a los términos utilizados por la directiva, incluida la referencia a la buena fe contenida en la definición de cláusula abusiva.

También se señaló que el requerimiento de transparencia debía mantenerse, debiendo dejarse en claro que los organismos encargados de cumplimiento de estas normas pueden hacer uso de sus facultades en contra de las cláusulas que no satisfacen este requerimiento y, además, se aconsejó agregar dentro de la definición de transparencia que la cláusula si es escrita debe ser legible.

Respecto de la definición de consumidor, se recomendó derogar toda referencia en UCTA a los consumidores y, a la vez, simplificar la legislación haciéndola aplicable solo a contratos entre proveedores y consumidores ${ }^{95}$. En este sentido, la recomendación fue seguir el concepto de consumidor utilizado en la directiva 93/13, ya que es el concepto adoptado por las directivas europeas relativas a la protección al consumidor, dejando esta noción restringida a las personas naturales.

Además, se sugirió extender la protección al campo de los anuncios dirigidos a los consumidores. La Comisión sostuvo que muchos de estos anuncios son capaces de provocar algún efecto pernicioso para los consumidores, pe-

${ }^{95}$ No se mantuvo la recomendación prevista en los informes de 2005 en orden a incorporar a los pequeños empresarios como consumidores, dado que el gobierno de Reino Unido no ha proyectado reformas en dicho ámbito. Unfair Terms in Consumer Contracts: a new approach? Issues Paper a Joint Issues Paper, p. 6. 
ro al no ser cláusulas contractuales, los órganos respectivos no pueden tomar acción alguna en su contra dado que UTCCR solo resultaba aplicable a cláusulas contractuales. UCTA no requería para su aplicación que se trate de una cláusula con dicho status, por lo que si una exclusión de responsabilidad tenía lugar en un anuncio, fuera del contexto de un contrato, UCTA protegía al consumidor. En vista de lo anterior, se recomendó que la nueva legislación resulte aplicable también a anuncios.

En relación con la carga de la prueba, considerando la dificultad que reviste para el consumidor probar la abusividad de una cláusula, lo que se propuso fue establecer el deber para el tribunal de declararlo de oficio. Esto vendría a cumplir con la decisión del Trique obliga a los tribunales de los Estados a declarar la abusividad de una cláusula de oficio aun si el consumidor no planteó dicho asunto ${ }^{96}$.

Las recomendaciones efectuadas por la Comisión fueron aceptadas por el gobierno de Reino Unido e incorporadas a un proyecto de ley denominado "Consumer Rights Bill 2014"97

${ }^{96}$ Pannon GSM Zrt./Erzsébet Sustikné Gy rfi, (2009): "El juez nacional deberá examinar de oficio el carácter abusivo de una cláusula contractual tan pronto como disponga de los elementos de hecho y de Derecho necesarios para ello. Cuando considere que tal cláusula es abusiva se abstendrá de aplicarla, salvo si el consumidor se opone. Esta obligación incumbe asimismo al juez nacional en el momento de la apreciación de su propia competencia territorial".

${ }^{97} \mathrm{El}$ proyecto de ley puede ser revisado en www.publications.parliament.uk/pa/bills/ cbill/2013-2014/0161/14161.pdf [fecha de consulta: 10 de mayo de 2015].

el cual ingresó al Parlamento el 24 de enero de 2014 y se convirtió en ley, con la sanción o aprobación real (Royal Assent $)^{98}$ el 26 de marzo de 2015, aunque la mayoría de sus disposiciones comenzaron a regir el 1 de octubre de 2015.

\section{Consumer Rights Act $2015^{99}$}

CRA ha significado una gran reforma para el Derecho de Consumo inglés. De hecho, si se revisa la legislación a partir la década de 1960 hasta ahora, se podría decir que ha sido la reforma más extensa y significativa en términos de la cantidad de materias que abarca y la cantidad de reformas que realiza a la legislación anterior. En ese sentido, se ha llegado a decir que se trata de una verdadera codificación ${ }^{100}$. En efecto, CRA reforma (reemplaza total o parcialmente) siete cuerpos legislativos, a saber: $\mathrm{Su}-$ pply of Goods (Implied Terms) Act 1973, Sale of Goods Act 1979, Supply of Goods and Services Act 1982, Sale and Supply of Goods Act 1994, Sale and Supply of Goods to Consumers Regulations 2002, Unfair Contract Terms Act 1977, Unfair Terms in Consumer Contracts

${ }^{98}$ Generalmente, un proyecto de ley se transforma en una ley (Act of Parliament) cuando la Reina lo aprueba, es lo que se conoce como Royal Assent, aunque la mayoría de las veces comenzará a regir posteriormente.

${ }^{99}$ En el Derecho inglés es usual que los Act of Parliament vengan acompañados de un documento que no forma parte de la ley, destinado a explicar los términos de la misma con el fin de hacerla más accesible. Se trata de las Explanatory Notes. Pues bien, a continuación, se explican los principales rasgos de la CRA tomando como base las Consumer Rights Act 2015 Explanatory Notes, elaboradas por el BIS.

${ }^{100}$ Riefa (2015), pp. 20-22. 
Regulations 1999, además de otras leyes que no tienen como objetivo central materias de consumo, pero que igualmente se ven afectadas por el cambio legislativo $^{101}$. La ley implementa las siguientes directivas: directiva 1999/44/ CE sobre determinados aspectos de la venta y las garantías de los bienes de consumo; directiva $93 / 13$; algunas disposiciones de la directiva 2011/83/EU sobre los derechos de los consumidores. También implementa algunas disposiciones relativas a la aplicación de los siguientes reglamentos y directivas: Reglamento 2006/2004 sobre la cooperación entre las autoridades nacionales encargadas de la aplicación de la legislación de protección de los consumidores $^{102}$; reglamento $765 / 2008$ por el que se establecen los requisitos de acreditación y vigilancia del mercado relativos a la comercialización de los productos; directiva 2001/95/EC relativa a la seguridad general de los productos y directiva 98/27/EC; directiva 98/27/CE del Parlamento europeo y del Consejo de 19 de mayo de 1998, relativa a las acciones de cesación en materia de protección de los intereses de los consumidores.

Lo más relevante de CRA es que reúne en una sola ley varios importan-

${ }^{101} \mathrm{Al}$ respecto véase www.legislation.gov. uk/changes/affecting/ukpga/2015/15?resultscount $=50 \&$ sort $=$ affected-year-number\&page $=1$ [fecha de consulta: 12 de mayo de 2015].

${ }^{102}$ Reglamento (CE) No 2006/2004 del Parlamento europeo y del Consejo de 27 de octubre de 2004 sobre la cooperación entre las autoridades nacionales encargadas de la aplicación de la legislación de protección de los consumidores ("Reglamento sobre la cooperación en materia de protección de los consumidores") Diario Oficial de la Unión Europea L 364 de 9 de diciembre de 2004, pp. 1-19. tes aspectos relativos a la protección del consumidor. Entre otras cosas, esta ley regula: los contratos relativos a bienes, servicios y contenido digital; cláusulas abusivas en contratos de consumo; introduce caminos más fáciles para consumidores, pequeñas y medianas empresas a fin de que estos puedan impug nar conductas contrarias a la libre competencia; consolida las facultades de ciertos órganos destinados a velar por el cumplimiento de la ley para que estos investiguen potenciales infracciones del Derecho de Consumo dándoles flexibilidad para tomar la acción más apropiada para el caso concreto.

La Ley se divide en tres partes. La parte 1 se refiere a los contratos de consumo de bienes, servicios y contenidos digitales; la parte 2 cubre las cláusulas abusivas y la parte 3 contiene disposiciones varias y generales.

En lo que se refiere al ámbito de aplicación territorial CRA se aplica, en general, a Inglaterra y Gales, Escocia e Irlanda del Norte, salvo algunas secciones que no se aplican a estos dos últimos.

En el ámbito de las cláusulas abusivas, esta ley cambió el escenario legislativo anterior, removiendo los conflictos y la complejidad derivada de la coexistencia de UCTA y UTCCR. Las disposiciones de UCTA sobre contratos de consumo (B2C) fueron reemplazadas por CRA, subsistiendo en lo demás (B2B y C2C). UTCCR fue reemplazada por CRA completamente, constituyendo esta última, como se apuntó algunos párrafos atrás, la nueva implementación de la directiva 93/13.

En el marco del tratamiento que la nueva ley da a las cláusulas abusi- 
vas, a continuación se tratan aspectos considerados relevantes.

En lo que tiene relación con el ámbito de aplicación material, la sección 61 de la ley establece que la Parte 2 referida a cláusulas abusivas- se aplica a contratos celebrados entre consumidores y proveedores, denominados por disposición expresa de la misma ley, contratos de consumo. Esta parte también se aplica a avisos o anuncios de consumo (consumer notice) ${ }^{103}$.

De conformidad con la sección 61, relativa a los contratos y anuncios, cubiertos por la ley, se aplica a cláusulas negociadas y a las no negociadas. Esto no lo dice de forma expresa, pero se concluye dado que no excluye de su campo de aplicación a las cláusulas individualmente negociadas. Por otro lado, lo mismo se desprende de la defi298 nición de cláusula abusiva, que siendo casi idéntica a la contenida en el art. 3.1 de la directiva 93/13 no exige que se trate de "cláusulas contractuales que no se hayan negociado individualmente"104, Además, así lo recomendaron los informes de la Law Commission que sirvieron de base al proyecto de ley y así lo señalan las respectivas Explanatory Notes.

En cuanto a la definición de consumidor, se establece que debe tratarse de un individuo (persona natural) ac-

${ }^{103}$ Dichos avisos pueden ser contractuales o no contractuales, escritos o verbales, y consisten en un anuncio u otra comunicación que es razonable suponer está destinada a ser leída por un consumidor.

${ }^{104}$ CRA, Sección 62(4) "A term is unfair if, contrary to the requirement of good faith, it causes a significant imbalance in the parties' rights and obligations under the contract to the detriment of the consumer". tuando con fines total o principalmente fuera de su negocio, empresa, oficio o profesión. Sobre la base de ello, no es posible considerar consumidor a las empresas, sin importar su tamaño, si actúan conforme a una actividad accesoria ni la habitualidad con que se realiza la misma. A su vez, proveedor se define como aquella persona que actúa con fines relacionados a su negocio, empresa, oficio o profesión, sea que actúe personalmente o a través de otra persona en su nombre o por su cuenta ${ }^{105}$.

La ley establece reglas generales de acuerdo con las cuales una cláusula se considera justa o equitativa (fairness of contract terms). Por ejemplo, define cláusula abusiva y enuncia los elementos que se deben tomar en cuenta para determinar si una cláusula es justa o equitativa ${ }^{106}$. No establece sobre quién recae la carga de la prueba, pero sí establece que los tribunales deben considerar la justicia o equidad de una cláusula, incluso, si ninguna de las partes lo ha planteado ${ }^{107}$.

Luego, en uno de sus anexos, estatuye las cláusulas contractuales que pueden ser declaradas abusivas con una lista indicativa y no exhaustiva de veinte hipótesis (tres hipótesis más que la lista contenida en la directiva 93/13) ${ }^{108}$. Se trata de una lista gris, es decir, que no son automáticamente consideradas abusivas, pero sirven de base para acudir al tribunal con el fin de obtener

${ }^{105}$ CRA Parte 2, sección 76(2) y Parte 1, sección 2(2) (3).

${ }^{106}$ CRA sección 62. Cláusula abusiva se define como aquella que siendo contraria a los requerimientos de la buena fe, causa un significativo desequilibrio entre los derechos de las partes contratantes en detrimento del consumidor

${ }^{107}$ CRA, sección 71(2).

${ }^{108} \mathrm{CRA}$, anexo 2, parte 1, párrafos 5, 12 y 14 . 
la aplicación de una evaluación de justicia o equidad para el caso particular, conforme al cual puede ser declarada abusiva. Adicionalmente, la Parte 2 de la ley contiene una hipótesis de cláusula que debe ser declarada abusiva. Se trata de la implementación de art. 15 de la directiva 2002/65/EC según el cual será abusiva toda cláusula contractual o condición que ponga sobre el consumidor la carga de probar el cumplimiento de la totalidad o parte de las obligaciones que le incumben al proveedor en virtud de dicha directi$\mathrm{va}^{109}$. Por último, las cláusulas que excluyen o restringen la responsabilidad por muerte o lesiones personales por negligencia del proveedor están prohibidas y no producen efecto alguno ${ }^{110}$.

Por otro lado, de conformidad a la directiva 93/13, se prevén algunas excepciones a la evaluación de equidad o justicia de una cláusula (exclusion from assessment of fairness). Se trata de las cláusulas que especifican el objeto principal del contrato y las que se refieren a la adecuación del precio. Lo interesante es que CRA precisa estas excepciones e incorpora un término nuevo en el ámbito de la regulación de cláusulas abusivas en el Derecho inglés, cual es prominent, término cuya traducción más adecuada, ya empleada en el apartado anterior, es la de "notorio(a)" dado que se refiere a qué tan visible o evidente debe ser la cláusula.

${ }^{109}$ CRA, parte 2, sección 63(6) y (7), que implementa el art. 15 directiva 2002/65/CE del Parlamento europeo y del Consejo de 23 de septiembre de 2002 relativa a la comercialización a distancia de servicios financieros destinados a los consumidores, y por la que se modifican la directiva 90/619/CEE del Consejo y las directivas 97/7/CE y 98/27/CE.

${ }^{110}$ CRA, parte 2, secciones 65 y 66.
En efecto, de conformidad a la sección 64, estas cláusulas se encontrarán excluidas del examen de equidad solo si son transparentes y notorias. Una cláusula es transparente si se expresa en un lenguaje claro e inteligible y, además, es legible y notoria si sometida a un consumidor promedio este es capaz de darse cuenta de ella. De conformidad a esto, en orden a determinar si las cláusulas inicialmente excluidas conforme a la directiva 93/13 son evaluables bajo el test de equidad o justicia, el tribunal primero debe considerar si la respectiva cláusula es transparente y notoria, y si lo es, entonces se genera la excepción, de lo contrario es evaluable.

Para velar por el cumplimiento de estas normas, de conformidad con el art. 7 de la directiva 93/13, se establece en la sección 70 que se conferirán facultades a la CMA y a otros órganos coordinados por esta, las que están establecidas en el anexo 3. Según esto la CMA, y los otros organismos, pueden investigar y solicitar una orden judicial para prevenir el uso de ciertas cláusulas que se consideran ser abusivas, no transparentes o incapaces de producir efecto por estar prohibidas (void). En el ejercicio de sus facultades estos órganos también pueden recolectar y hacer pública cierta información relacionada con las acciones tomadas en contra de alguna cláusula en particular, pudiendo emitir la CMA alguna guía al respecto ${ }^{111}$.

${ }^{111}$ Estas facultades se ven complementadas por la sección 13 (7) y (8) del anexo 5 de CRA. Hay otros medios de control establecidos en la parte 8 de la Enterprise Act 2002, por ejemplo, acciones privadas de los consumidores presentadas ante los tribunales. 
Hasta aquí, se puedever un resumen de lo que CRA ha venido a hacer en el ámbito de las cláusulas abusivas. Naturalmente, la situación legal preexistente de superposición de regulación y esta nueva legislación que reforma dicho escenario puede resultar un tanto confuso por lo que el siguiente paralelo entre la regulación anterior y la actual puede ayudar a aclarar el panorama.

\section{Paralelo. \\ Antigua y actual regulación de las cláusulas abusivas en el Derecho inglés}

\begin{tabular}{|c|c|c|}
\hline UCTA 1970 & UTCCR 1999 & CRA 2015 \\
\hline $\begin{array}{l}\text { Contiene disposiciones apli- } \\
\text { cables a Inglaterra, Gales e Ir- } \\
\text { landa del Norte, otras aplica- } \\
\text { bles solo a Escocia, y algunas } \\
\text { aplicables a todo Reino Unido. }\end{array}$ & $\begin{array}{l}\text { Se aplica a todo Reino Uni- } \\
\text { do. }\end{array}$ & $\begin{array}{l}\text { Se aplica, en general, a todo } \\
\text { Reino Unido. Algunas de } \\
\text { sus secciones no se aplican } \\
\text { a Escocia e Irlanda del Nor- } \\
\text { te. }\end{array}$ \\
\hline $\begin{array}{l}\text { Consumidor es quien celebra } \\
\text { el contrato fuera de curso de } \\
\text { su negocio teniendo como } \\
\text { contraparte a quien lo hace } \\
\text { dentro del curso del suyo. } \\
\text { Una empresa puede ser con- } \\
\text { siderada consumidor. }\end{array}$ & $\begin{array}{l}\text { Consumidor es toda perso- } \\
\text { na natural que actúa con un } \\
\text { propósito ajeno a su nego- } \\
\text { cio, empresa o profesión. }\end{array}$ & $\begin{array}{l}\text { Consumidor es un indivi- } \\
\text { duo (persona natural) que } \\
\text { actúa con propósitos total } \\
\text { o principalmente ajenos a } \\
\text { su negocio, empresa, oficio } \\
\text { o profesión. }\end{array}$ \\
\hline $\begin{array}{l}\text { Businessincluye una actividad } \\
\text { profesional y las actividades } \\
\text { de cualquier departamento de } \\
\text { gobierno. }\end{array}$ & $\begin{array}{l}\text { Sellerorsupplierse refiere atoda } \\
\text { persona natural o jurídica, } \\
\text { ya sea pública o privada } \\
\text { que, en contratos cubiertos } \\
\text { por UTCCR, esté actuando } \\
\text { con propósitos relacionados } \\
\text { a su negocio, empresa o } \\
\text { profesión. }\end{array}$ & $\begin{array}{l}\text { Traderse refiere a una perso- } \\
\text { na que actúa con propósitos } \\
\text { relativos a su negocio, em- } \\
\text { presa, oficio o profesión, } \\
\text { ya sea personalmente a tra- } \\
\text { vés de otra persona actuan- } \\
\text { do en su nombre o por su } \\
\text { cuenta. }\end{array}$ \\
\hline $\begin{array}{l}\text { Aplicable a contratos de con- } \\
\text { sumo y a contratos celebrados } \\
\text { entre proveedores. En algu- } \\
\text { nos casos, aplicable a contratos } \\
\text { entre consumidores. } \\
\text { Se excluyen del campo de } \\
\text { aplicación algunos tipos de con- } \\
\text { tratos, por ejemplo: los con- } \\
\text { tratos de seguro y contratos re- } \\
\text { lativos a bienes raíces. }\end{array}$ & $\begin{array}{l}\text { Aplicable sólo a contratos de } \\
\text { consumo. } \\
\text { No hay exclusiones. }\end{array}$ & $\begin{array}{l}\text { Aplicable sólo a contratos de } \\
\text { consumo. } \\
\text { La sección } 65 \text { no se aplica a } \\
\text { los contratos de seguro ni a los } \\
\text { contratos relativos a bienes raí- } \\
\text { ces. }\end{array}$ \\
\hline
\end{tabular}




\begin{tabular}{|c|c|c|}
\hline $\begin{array}{l}\text { Aplicable tanto a cláusulas li- } \\
\text { bremente negociadas como no } \\
\text { negociadas que buscan excluir } \\
\text { o limitar la responsabilidad del } \\
\text { proveedor. }\end{array}$ & $\begin{array}{l}\text { Aplicable a cláusulas no ne- } \\
\text { gociadas. } \\
\text { No quedan incluidas las cláu- } \\
\text { sulas que digan relación con la } \\
\text { definición del objeto principal } \\
\text { del contrato, ni con la adecua- } \\
\text { ción entre el precio y los bie- } \\
\text { nes o servicios que deban pro- } \\
\text { porcionarse como contraparti- } \\
\text { da, en la medida en que estén } \\
\text { redactadas en forma clara. }\end{array}$ & $\begin{array}{l}\text { Aplicable tanto a cláusulas } \\
\text { libremente negociadas co- } \\
\text { mo no negociadas. } \\
\text { No quedan incluidas las cláu- } \\
\text { sulas que tengan relación con } \\
\text { la definición del objeto prin- } \\
\text { cipal del contrato, ni con la ade- } \\
\text { cuación entreel precioylos bie- } \\
\text { nes o servicios que deban pro- } \\
\text { porcionarse como contrapar- } \\
\text { tida, en la medida en que estas } \\
\text { sean transparentes y notorias. }\end{array}$ \\
\hline $\begin{array}{l}\text { Ciertas cláusulas quedan auto- } \\
\text { máticamente sin efecto. } \\
\text { Todas las demás cláusulas } \\
\text { pueden ser válidas si cumplen } \\
\text { con el requerimiento o test de } \\
\text { razonabilidad (reasonableness). }\end{array}$ & $\begin{array}{l}\text { No se prevén hipótesis de cláu- } \\
\text { sulas que queden automáti- } \\
\text { camente sin efecto. Las clau- } \\
\text { sulas se someten a un test o } \\
\text { evaluación de justicia o equidad } \\
\text { (fairness). }\end{array}$ & $\begin{array}{l}\text { Ciertas cláusulas quedan au- } \\
\text { tomáticamente sin efecto. } \\
\text { Las demás cláusulas se so- } \\
\text { meten a un test o evaluación } \\
\text { de justicia o equidad (fair- } \\
\text { ness). }\end{array}$ \\
\hline No define cláusula abusiva & Define cláusula abusiva & Define cláusula abusiva \\
\hline $\begin{array}{l}\text { No contiene una lista de cláu- } \\
\text { sulas que pueden ser declaradas } \\
\text { abusivas }\end{array}$ & $\begin{array}{l}\text { Contiene una lista con dieci- } \\
\text { siete hipótesis de cláusulas que } \\
\text { pueden ser declaradas abusivas. }\end{array}$ & $\begin{array}{l}\text { Contiene una lista con } 20 \text { hi- } \\
\text { pótesis de cláusulas que pue- } \\
\text { den ser declaradas abusivas. }\end{array}$ \\
\hline $\begin{array}{l}\text { El proveedor es quien debe } \\
\text { demostrar que una cláusula } \\
\text { satisface el requerimiento de } \\
\text { razonabilidad. }\end{array}$ & $\begin{array}{l}\text { No se especifica quién debe } \\
\text { demostrar justicia o equidad } \\
\text { de una cláusula. }\end{array}$ & $\begin{array}{l}\text { No se especifica quién debe } \\
\text { demostrar justicia o equidad } \\
\text { de una cláusula. }\end{array}$ \\
\hline $\begin{array}{l}\text { No contiene el principio de } \\
\text { transparencia }\end{array}$ & $\begin{array}{l}\text { Incorpora el principio de trans- } \\
\text { parencia exigiendo que las cláu } \\
\text { sulas se expresen de manera cla- } \\
\text { ra y comprensible. }\end{array}$ & $\begin{array}{l}\text { Contiene el principio de trans- } \\
\text { parencia expresando que una } \\
\text { cláusula es transparente en } \\
\text { tanto se expresa de formas cla- } \\
\text { ra, comprensible y además es } \\
\text { legible y notoria. }\end{array}$ \\
\hline $\begin{array}{l}\text { No establece control preventivo } \\
\text { de cláusulas. }\end{array}$ & $\begin{array}{l}\text { Establece controles preventi- } \\
\text { vos. }\end{array}$ & $\begin{array}{l}\text { Establece controles preventi- } \\
\text { vos. }\end{array}$ \\
\hline
\end{tabular}

\section{IMPRESIONES FINALES}

En el ámbito de las cláusulas abusivas, el cambio legislativo que establece CRA no solo superó el problema de superposición normativa preexistente, sino que, igualmente, reviste gran importancia porque supera el nivel de protección que exige la directiva 93/13. Así, CRA resulta aplicable tanto a cláusulas predispuestas como a cláusulas libremente negociadas; las cláusulas que excluyen o restringen la responsabilidad por muer- te o lesiones personales debido a negligencia del proveedor están prohibidas; las cláusulas que digan relación con la definición del objeto principal del contrato o con la adecuación del precio se excluyen solo en la medida en que estas sean transparentes y notorias; incorpora tres nuevas hipótesis a la lista gris de cláusulas; y, se establece de manera expresa el deber del tribunal de considerar de oficio la abusividad de la cláusula. 
Se puede apreciar que esta ley incorporó, en su mayoría, las recomendaciones de los informes evacuados por la Law Commission. Sin embargo, llama la atención que, pudiendo observarse claramente la tendencia a aumentar el umbral protección con respecto a la directiva $93 / 13$ y buscando igualar hacia arriba la protección ofrecida por la legislación anterior, no se haya acogido la recomendación realizada en el año 2005 de incorporar a microempresarios como consumidores. En ese sentido, bajo la legislación anterior la protección era mayor y ahora se ve mermada por cuanto solo pueden ser considerados consumidores, en este ámbito, quienes son personas naturales.

Lo anterior revela una verdadera inconsistencia, sobre todo si se acepta como paradigma del Derecho de Con302 sumo la protección de la parte débil, ya que sobre esa base es muy difícil evitar la extensión de la protección a pequeños empresarios $^{112}$.

\section{BIBLIOGRAFÍA CITADA}

BeAle, Hugh (2006), "English Law Reform and the Impact of European Private Law", in Stefan Vogenauer, Stephen Weatherill (eds.). The Harmonisation of European Contract Law. Implications for European Private Lawe, Business and Legal Practice. Oxford: Hart Publishing.

BEALE, Hugh(2004). "UnfairTermsin Contracts: Proposals for Reform in the UK". Journal of Consumer Policy. Vol. 27. New York: Springer.

BELL, John (2013). "Sources of Law", in Andrew Burrows (ed.). English Pri-

${ }^{112}$ Hondius (2004), p. 246. vate Law. 3rd Edition. Oxford: Oxford University Press.

Brownsword, Roger; Norma Hird and Geraint Howells (1999). Good Faith in Contract: Concept and Context. Aldershot: Dartmouth.

Carballo, Marta (2013). La protección del consumidor frente a las cláusulas no negociadas individualmente. Barcelona: Bosh.

Cartwright, John (2013). Contract Law. An Introduction to English Law of Contract for the Civil Lawyer. Second Edition. Oxford: Hart Publishing.

David, René y Camille Jauffret-SpinoSI (2010), Los grandes sistemas jurídicos contemporáneos. (trad.) Jorge Sánchez Cordero. Decimoprimera edición. México, D.F: Universidad Nacional Autónoma de México, Instituto de Investigaciones Jurídicas.

David, René (1980). English Law and French Law. London: Stevens \& Sons and Calcuta: Eastern Law House.

Ebers, Martin (2008). "Unfair Terms Directive 93/13 EC Consumer Law”, in Hans Schulte-Nölke, Christian Twigg Flesner and Martin Ebers (eds.), EC Compendium The Consumer Acquis and its transposition in the Member State. Munich: Sellier European Law Publishers.

Elliott, Catherine \& Frances QUinN (2011). Contract Law. 8th Edition. Harlow: Pearson Education Limited.

Hatzis, Aristides (2008). "An Offer You Cannot Negotiate: Some Thoughts on the Economics of Standard Form Consumer Contracts", in Hugh Collins, Society of European Contract Law. Standard Contract Terms in Europe: A Basis for and a Challenge to European Contract Law. Alphen aan den Rijn: Kluwer Law International. 
Hondius, Ewoud (2004), "The protection of the Weak Party in Harmonised European Contract Law: A Synthesis en Journal of Consumer Policy". Journal of Consumer Policy. Vol. 27. New York: Springer.

Hondius, Ewoud (1997). "Unfair contract terms: Towards a European Law Introduction". European Review of Private Law. Vol. 2. Alphen aan den Rijn.

Howells, Geraint (2002). "European Consumer Law -the Minimal and Maximal Harmonisation Debate and Pro Independent Consumer Law Competence", en Stefan Grundmann, Julien Stuyck (eds.). An Academic Greenpaper on European Contract Law. The Hague: Kluwer Law International.

Nebbia, Paolisa (2007). Unfair Contract Terms in European Law. A Study in Comparative and EC Lawe. Oxford: Hart.

Riefa, Christine (2015). "Codification: The Future of English Consumer Law?". Journal of European Consumer and Market Law (EuCML). Vol. 7. January. Viena.

Roppo, Vicezo (2011). "Del contrato con el consumidor a los contratos asimétricos: perspectivas del derecho contractual europeo". (trad.) María Angélica Moreno Cruz. Revista de Derecho Privado. Vol. 20. Bogotá: Universidad de Externado.

Slapper, Gary and David Kelly (2015). The English Legal System. 15th Edition. Abingdon: Routledge.

WALKER, Ronald et al. (2011). Walker \& Walker's English Legal System. 11th ed. Oxford: Oxford University Press.

Willett, Chris (1997). "The Directive on Unfair Terms in Consumer Contracts and its implementation in the United Kingdom". European Review of Private Law. Vol. 2. Alphen aan den Rijn.

Wilson, Stephen, Helen Rutherford, Tony Storey, Natalie Wortley (2014). English Legal System. Oxford: Oxford University Press.

WhitTaker, Simon (2008). "El precedente en el Derecho inglés: una visión desde la ciudadela". (trad) Cristián Banfi del Río. Revista Chilena de Derecho. $\mathrm{N}^{\mathrm{O}}$ 1. Santiago.

Zimmermann, Reinhard and Simon Whittaker (2000). Good Faith in European Contract Law. Cambridge: Cambridge University Press.

Zweigert, Konrad \& Hein Kötz (1998), An Introduction to Comparative Law. (trad.) Tony Weir. 3rd edition. Oxford: Oxford University Press.

\section{Jurisprudencia citada}

Pannon GSM Zrt. v. Erzsébet Sustikné Gy rfi. Tribunal de Justicia de la Unión Europea. 4 de junio de 2009. Luxemburgo. C-243/08. CVRIA: ECLI:EU:C:2009:350

R \& B Customs Brokers Co Ltd v. United Dominions Trust Ltd. England and Wales Court of Appeal (Civil Division). December 1987. London. Westlaw UK: 1988 R.T.R. 134.

\section{Normas citadas}

Consumer Rights Act. 2015 c. 15. TSO. 26.03.2015.

Directiva 93/13/CEE del Consejo, de 5 de abril de 1993, sobre las cláusulas abusivas en los contratos celebrados con consumidores. DOUE. L $95 \mathrm{de}$ 21 de abril de 1993. 
Directiva 1999/44/CE del Parlamento Europeo y del Consejo, de 25 de mayo de 1999, sobre determinados aspectos de la venta y las garantías de los bienes de consumo. DOUE. L 171 de 7 de julio de 1999.

Directiva 2001/95/CE del Parlamento Europeo y del Consejo, de 3 de diciembre de 2001, relativa a la seguri dad general de los productos. DOUE. L 11 de 15 de enero de 2002.

Directiva 2006/114/CE del Parlamento Europeo y del Consejo, de 12 de diciembre de 2006 sobre publicidad engañosa y publicidad comparativa. DOUE. L 376 de 27 de diciembre de 2006.

Directiva 2011/83/UE del Parlamento Europeo y del Consejo, de 25 de octubre de 2011, sobre los derechos de los consumidores, por la que se mo-
Directiva 98/27/CE del Parlamento Europeo y del Consejo de 19 de mayo de 1998 relativa a las acciones de cesación en materia de protección de los intereses de los consumidores. DOUE. L 166 de 11 de junio de 1998.

Enterprise Act 2002. c.40. TSO. 7.11.2002.

European Communities Act 1972. c.68. HMSO. 17.10.1972.

Law Commissions Act 1965. c.22. HMSO. 15.06.1965.

Reglamento (CE) No 765/2008 del Parlamento Europeo y del Consejo, de 9 de julio de 2008, por el que se establecen los requisitos de acreditación y vigilancia del mercado relativos a la comercialización de los productos y por el que se deroga el Reglamento (CEE) No 339/93. DOUEL-2008-81669. 9 de julio de 2008.

The Unfair Terms in Consumer Contracts Regulations 1994. No 3159. TSO. 01.07.1995.

The Unfair Terms in Consumer Contracts Regulations 1999. No 2083. TSO. 01.10.1999. 97/7/CE del Parlamento Europeo y del Consejo. DOUE. L 304 de 22 de noviembre de 2011.
Unfair Contract Terms Act 1977. HMSO. 26.10.1977. 